\title{
MICROCONTROLLER BASED SMART HOME WITH SECURITY USING GSM TECHNOLOGY
}

\author{
F. Shawki ${ }^{1,2}$, M. El-Shahat. Dessouki ${ }^{1,3}$, A. I. Elbasiouny ${ }^{4}$, A.N. Almazroui ${ }^{5}$, F. M. R. Albeladi ${ }^{5}$ \\ ${ }^{I}$ Assistant Professor, Electrical Engineering Department, Faculty of Engineering KAU, Rabigh, Saudi Arabia \\ ${ }^{2}$ Assistant Professor, Electronics \& Electrical CommunicationsDept., Faculty of Electronic Eng., Menofiya \\ University, Egypt \\ ${ }^{3}$ Assistant Professor, Electrical Engineering Department, Faculty of Engineering, Port said University, Egypt \\ ${ }^{4}$ Ph.D. Student, Electrical Engineering Department, Faculty of Engineering KAU, Rabigh, Saudi Arabia \\ ${ }^{5}$ BSC. Student, Electrical Engineering Department, Faculty of Engineering KAU, Rabigh, Saudi Arabia
}

\begin{abstract}
Smart home is a house that uses information technology to monitor the environment, control the electric appliance and communicates with the outer world. Smart home is a complex technology, at the same time it is developing. A smart home automation system has been developed to automatically achieve some activities performed frequently in daily life to obtain more comfortable and easier life environment. Security has becoming an important issue everywhere. Home security is becoming necessary nowadays as the possibilities of intrusion are increasing day by day. Safety from theft, and fire are the most important requirements of home security system for people. A traditional home security system gives the signals in terms of alarm. With the help of technology development, this research take a chance to implement these technologies to help people to protect and control their home appliance remotely. The purpose of this research is to create a system that make the surveillance of home devices easily. The technology that used in this research are GSM (Global System for digital mobile telecommunication ) and Microcontroller.The GSM module is used to communicate with the owner of the home whenever the sensor senses a fault, a specific message is sent to the owner in order to take a necessary action. The microcontroller is a tool that use a specific code to do some functions by using MikroC programmer. This project controls and monitors temperature, smoke, intrusion motion, magnetic lock door, garage door and irrigation. This project is expected to achieve, safety, save effort, save time, and easy devices control
\end{abstract}

Keywords: Smart home, GSM module, magnetic lock, microcontroller

\section{INTRODUCTION}

Smart home or automation home and security system has been developed last century, which began to be number one in the world for next decades. Smart home or home automation system using AT command and information technology to monitor home devices and control them (like temperature and motion) [1], [2]. Smart home is a complex system; however, it is very important because it can handle many home or office devices remotely and automatically. Moreover, this system allows the owner to control home devices from out home by using mobile network [3-5].

A smart home automation can turn on and off a fan, light, air condition and also can control the speed of fan with the help of a mobile controller according to user needs. Because mobile controlled home automation system provides a simpler solution of a Global System for Mobile GSM network. It will help to shut down the whole system, improves the convenience and comfort of the user while it provides security and energy efficiency[6-8]. GSM is used to digitalize a signal or data and transmit signal or data to the receiver. GSM module can be used to send the signal over a mobile in a fixed frequency to other mobile phone connected with the receiver. As the mobile network is available in most regions and low cost of message through mobile network, the SMS (short message service) is used to communicate with home devices. Protecting home, office and companies is one reason of exiting of all security companies. This project takes a chance to create a simple and smart system that protect homes, office and companies with less cost and high performance.

\section{PROPOSED SYSTEM}

There are many sensors we have used in this system (like temperature sensor, motion sensor, etc) . In order to make home energy efficient we also paid attention on home devices like fans and lights .Moreover, the system also focus on outside environment such as main door, garage door and irrigation. The heart of this system is a PIC18F452 microcontroller which is controlling home devices. If the thermometer feels an increase in room temperature then an electrical signal is sent to microcontroller, the microcontroller takes a necessary action like turn the fan on which work as an airconditioning. In case, there is a smoke in home smoke sensor detects the smoke then send a signal to microcontroller to turn the extractor on, to take out the smoke from home. In case, the owner away from home, 
he turns the motion sensor on . In order to detect the motion inside home while he away from home. If it detects a motion then send a signal to the microcontroller and microcontroller send a specific SMS message to the owner through GSM module. In order to take a necessary action like call the police station. Protection of home door is the important part in security system which is done in this system by using electromagnetic lock, LCD and keypad . The owner using keypad to enter the password which is displayed in LCD and if the password entered is correct then the electromagnetic lock is opened. Otherwise the password entered is wrong, the door will still locked .There are two ways of control for garage door which are wireless and manual. The first, wireless control is done by using GSM module technology that allow the owner to send a SMS message to GSM module then GSM module send a signal to microcontroller to open the garage door. The second, manual control which means there is a switch near garage door to open and close the door. The garden of house is the place where most people stay at rest time. This system including irrigation system for the garden, in order to take care of house garden. The irrigation is done by using pump which operates on timer.

\section{HARDWARE DESIGN AND DEVELOPMENT}

\subsection{Block Diagram}

Figure 1 illustrates a block diagram of the planned smart home and security system design with its hardware components involved and connections. The main components are: Microcontroller (PIC 18F452), GSM, Keypad, LCD, LM293 driver, Door locker, and power supply.

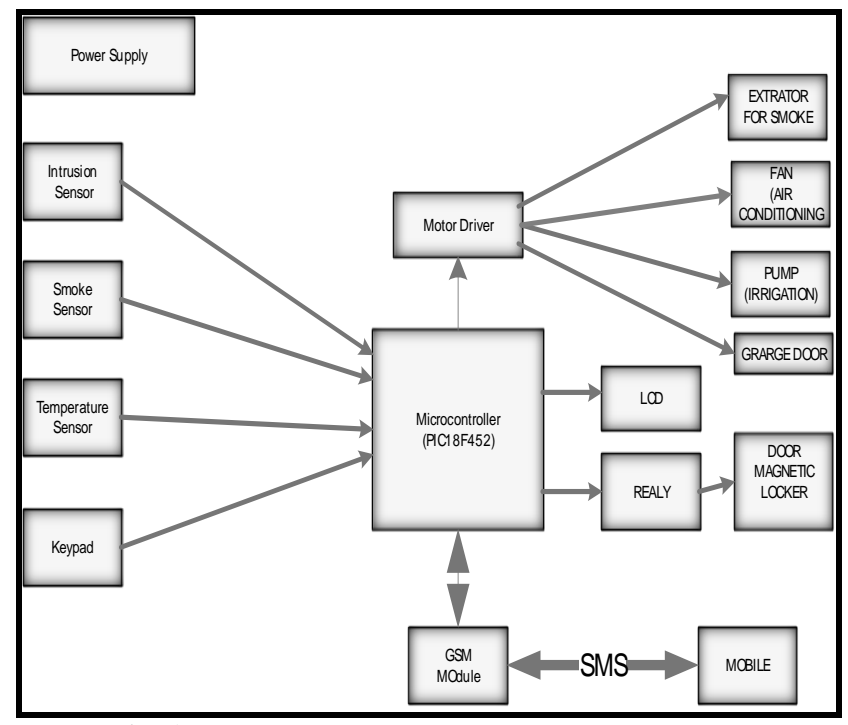

Fig-1: Block Diagram of the Proposed System

\subsection{Power Supply}

Every electrical circuit needs a source to operate and do its functions. In this project we have made our own power supply to meet all the needs of power. It has the feature of having different voltage levels of (such as $5 \mathrm{~V}, 12 \mathrm{~V},-12 \mathrm{~V}$, Adjustable (2-12) and USB port ) as shown in figure 2.

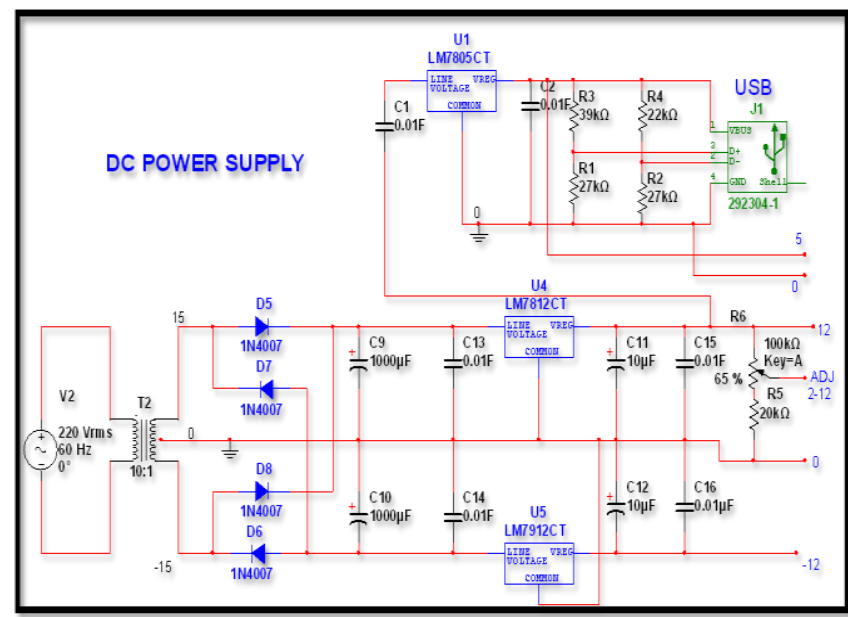

Fig-2: Circuit Diagram of the power supply

\subsection{Microcontroller Unit}

Microcontroller is a tool that use a specific code to perform all tasks and control of all home devices. We used "PIC18F452" microcontroller as the central controller unit of the system .we have chosen "PIC18F452" microcontroller for its easy programing, availability, and low cost. It has many features that support our project, (like 2 PWM 10-Bit flash type of program memory $32 \mathrm{~KB}$ program memory and other features see datasheet [9].

\subsection{GSM Module SIM (900)}

This device is used to communicate home with the owner through SMS "Short Message Service". GSM is a new technology that use mobile network to send and receive SMS. It accepts a SIM card and operate in mobile network. We used in this project SIM 900 which has many features. It is a module that works on different frequencies like 850 $\mathrm{MHz}, 900 \mathrm{MHz}, 1800 \mathrm{MHz}$ and $1900 \mathrm{MHz}$. It can be directly connected to PC Serial port and interfaced with PIC microcontroller [10].

\subsection{Temperature Sensing Circuit}

This circuit monitors real time temperature data from one room continuously to keep the room temperature at the desired level. The room has its setting temperature. Above this setting value, the microcontroller sends message to the user's mobile phone that the temperature is high through GSM in the same time microcontroller turns the aircondition on to restore the room temperature. We used the DS18B20 digital thermometer, it provides 9-bit to 12-bit Celsius temperature measurements and has an alarm function with nonvolatile user programmable upper and lower trigger points. Circuit diagram of DC18B20 is shown in figure 3 


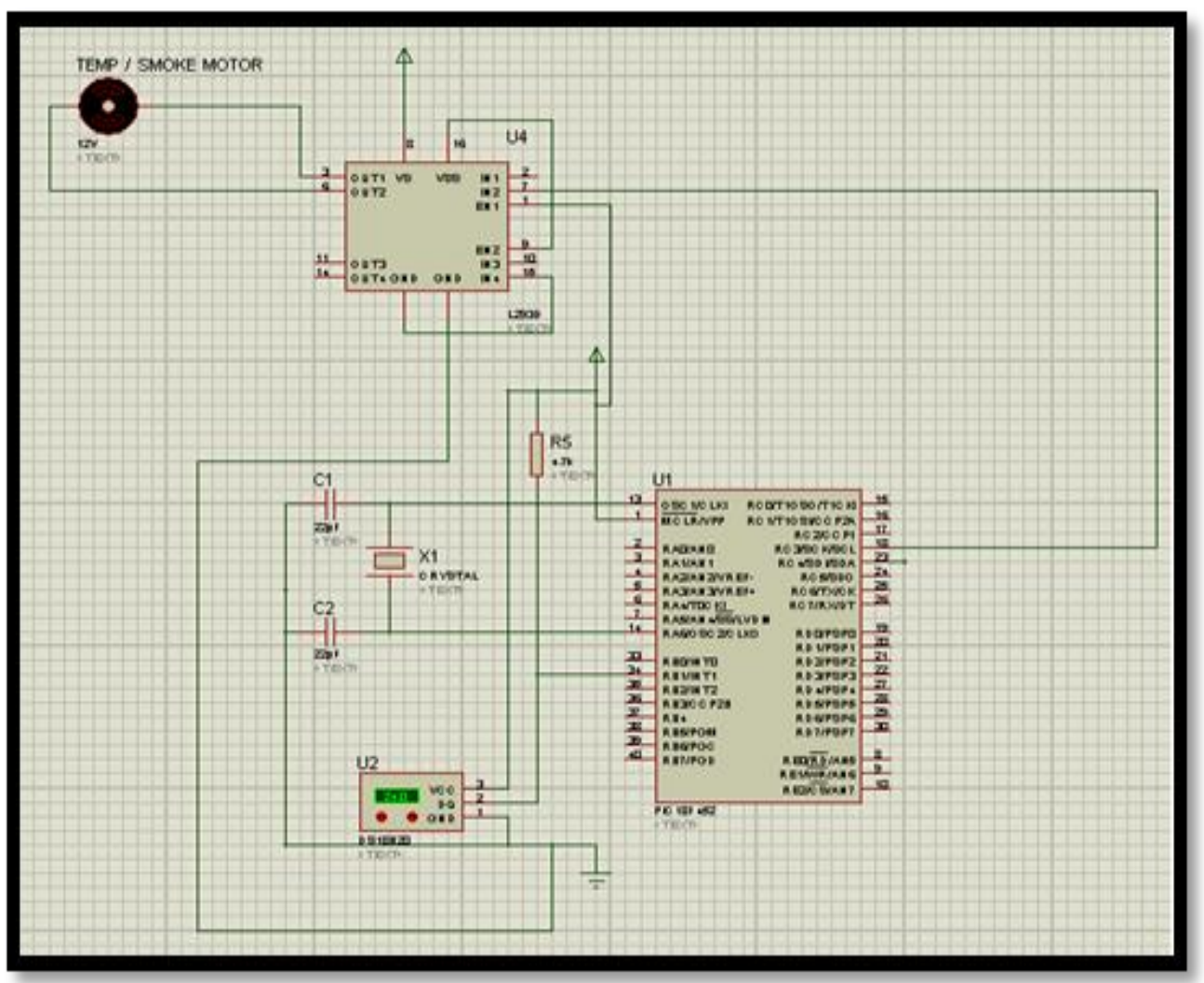

Fig-3: Temperature Circuit

\subsection{Smoke Detection Circuit}

This circuit has been used to detect smoke in case of fire in the corresponding room. In our project, we designed our own smoke detector circuit instead of buying smoke sensor for reducing cost purpose. With the advantage of electronics, we use a phototransistor and resistances as smoke sensor to detect the smoke in home; the circuit diagram is indicated in figure 4 . If there is a smoke in home the detector will sense it and send signal to the microcontroller to turn the extractor on in order to take smoke out of home, furthermore, it sends a message for the owner's mobile phone number through the GSM module in order to take necessary decision.

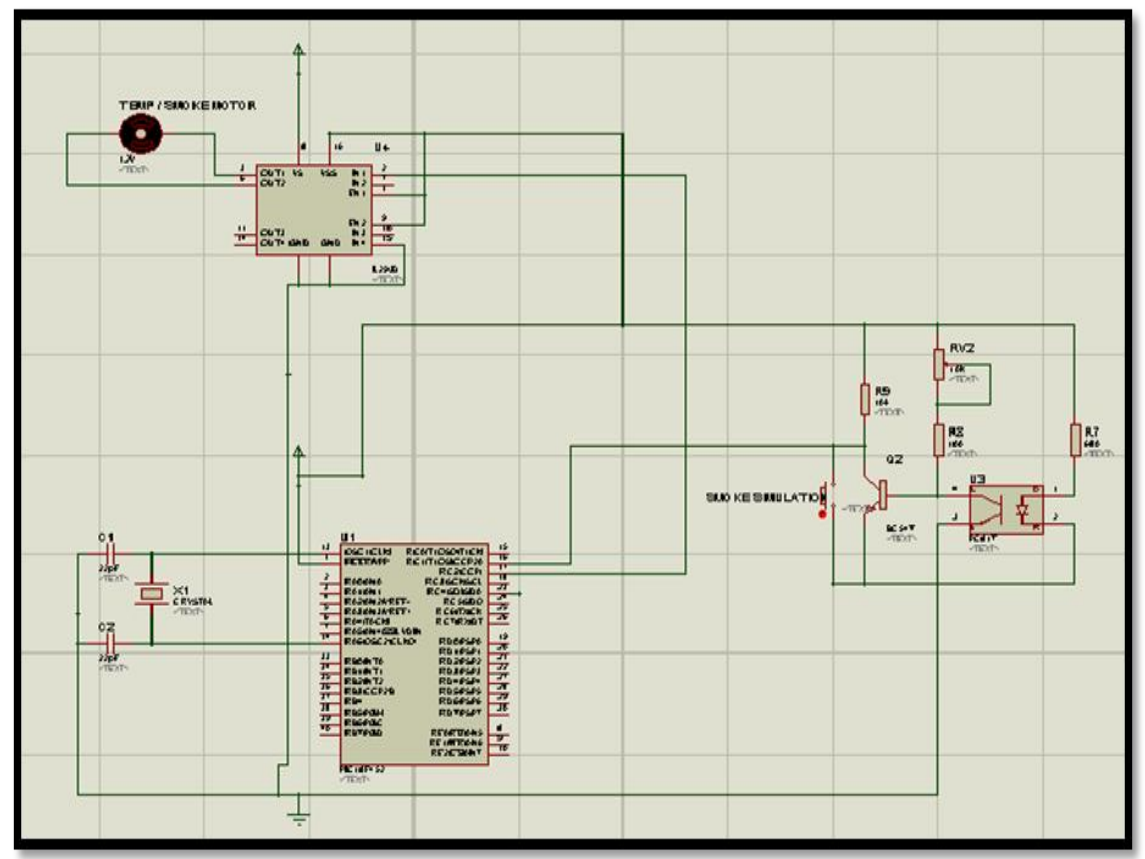

Fig-4: Smoke Sensor Circuit 


\subsection{Motion Detector Circuit}

PIR sensors allow you to sense motion, usually used to detect whether a human has moved in or out of the sensors range. They are often referred to as PIR, "Passive Infrared", "Pyroelectric", or "IR motion" sensors PIRs are basically made of a pyroelectric sensor, which can detect levels of infrared radiation. PIR sensor detects the motion inside home if there is any motion in its range. The signal is sent to microcontroller which has two actions, the first one is to send SMS message to the owner and the other is to turn the light on. We programmed two operating modes for PIR sensor. In case, there is no body at home the owner will turn the PIR sensor on when he/she left home by Keypad. He enters his password and press D to change the PIR sensor state. In case, the owner is in side home he changes the PIR sensor state in order to stop receiving messages.

\subsection{Magnetic Lock System}

An electromagnetic lock, magnetic lock, or maglock is a locking device that consists of an electromagnet and an armature plate. Typically, the electromagnet portion of the lock is attached to the main doorframe and a mating armature plate is attached to the main door. The two components are in contact when the door is closed. When the electromagnet is energized, a current passing through the electromagnet creates a magnetic flux that causes the armature plate to attract to the electromagnet, creating a locking action. Because the mating area of the electromagnet and armature is relatively large, the force created by the magnetic flux is strong enough to keep the door locked even under stress. When the owner arrives home, he must enter password to cut off the power on the electromagnet in order to open the door. If the password is wrong, the door will still lock.

\subsection{Garage Door}

In this project we came up with an idea that using mobile network in controlling the garage door by the owner for parking. The owner sends a SMS message to the microcontroller through GSM module then microcontroller sends a signal to door's motor to open.

\subsection{Irrigation}

In this project, we have implemented a simple irrigation system on house garden since some people has no time to take care of their gardens. This project will help them to take care of gardens without effort.

\section{SYSTEM SIMULATION AND RESULTS}

The overall poroposed smart home system containing main door, motion detection, smoke detection, temperature sensor, garage door, and irrigation system are simulated by using proteus7 window, Table 1 illustrates system functions status for our project.
Table -1: System functions status

\begin{tabular}{|l|l|l|}
\hline \multirow{2}{*}{ Sensor/Object } & Status \\
\cline { 2 - 3 } & ON & OFF \\
\hline Main door & Green & Black \\
\hline Motion sensor & Yellow & Black \\
\hline Smoke sensor & Yellow & Black \\
\hline Temperature sensor & Red & Black \\
\hline Garage door & Blue & Black \\
\hline Irrigation system & Red & Black \\
\hline
\end{tabular}

\subsection{Mani Door}

Protection of home main door is the important part in security system which done in this system by using electromagnetic lock in conjunction with keypad. The owner using keypad to enter the password which is display on LCD and if the password entered is correct then the electromagnetic lock is opened. Otherwise the password entered is wrong, the door will still locked, as shown in below figures $5,6,7$. 


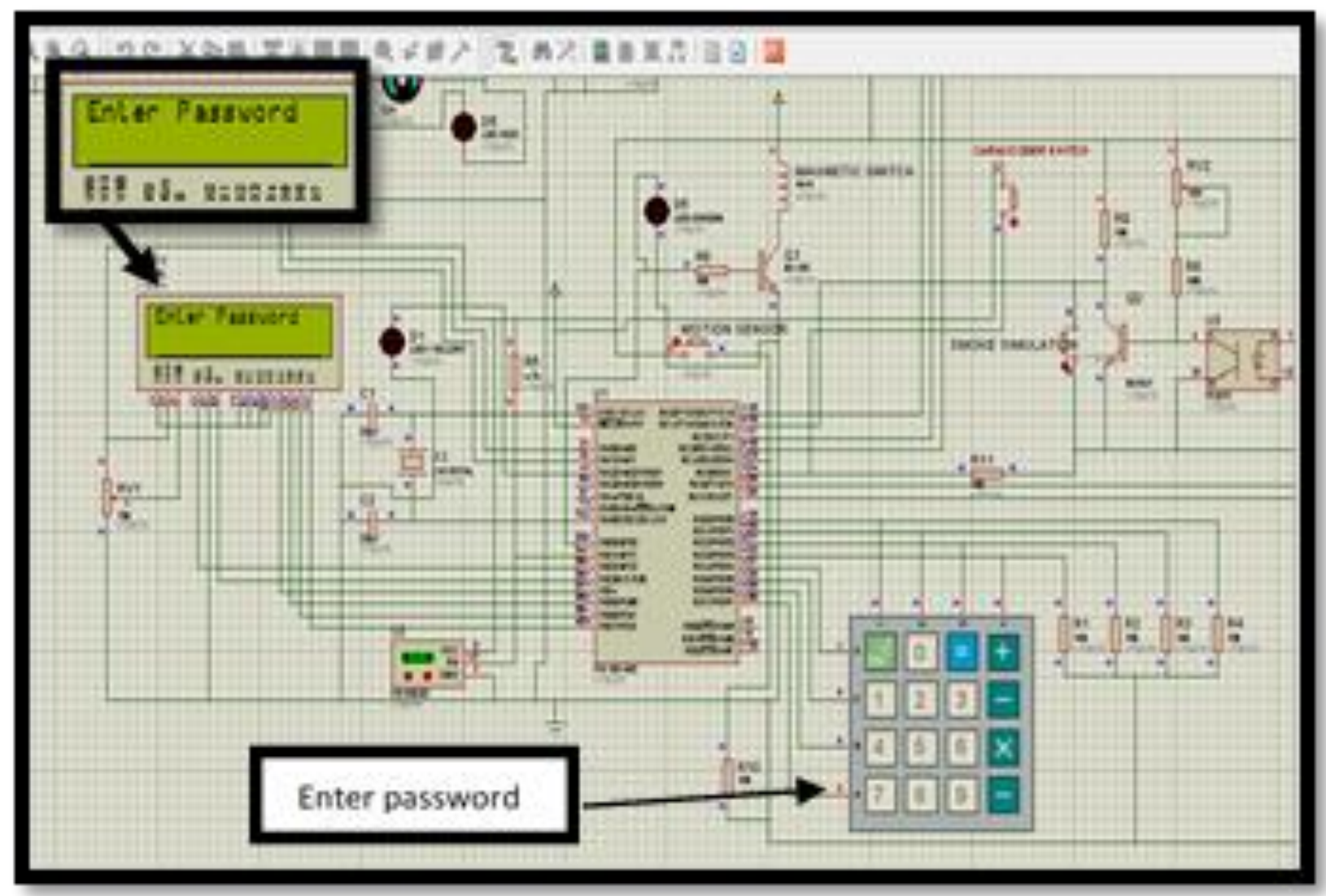

Fig-5: Entering password

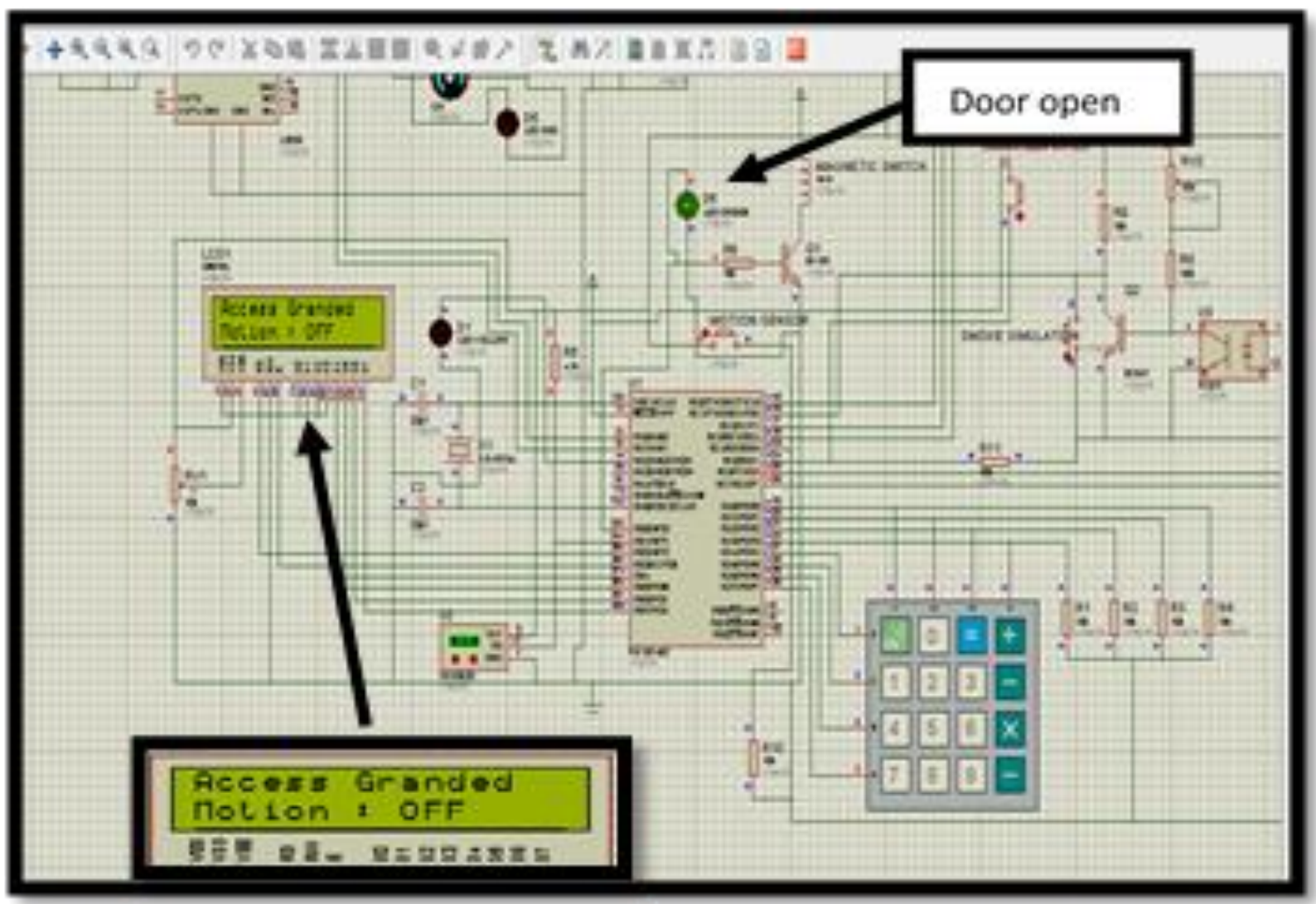

Fig-6: Access granted 


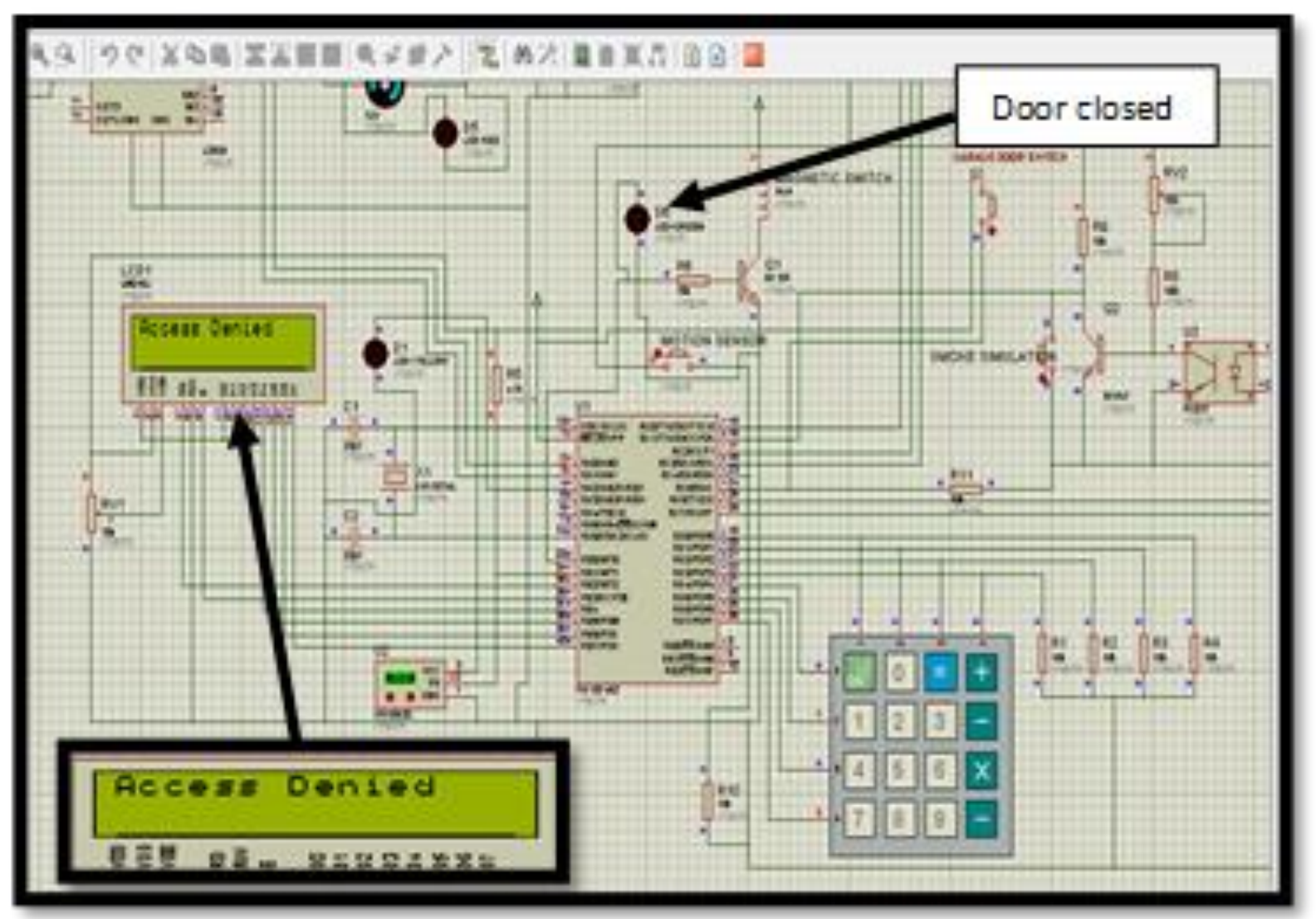

Fig-7: Access denied

\subsection{Motion Detection}

In case, the owner is away from home, he turns the motion sensor on in order to detect the motion inside home during his absence. If it detects a motion then it sends a signal to the microcontroller and microcontroller send a specific
SMS message to the owner through GSM module in order to take a necessary action like call the police station and turn lights on in parallel. Figure 8 indicate this condition.

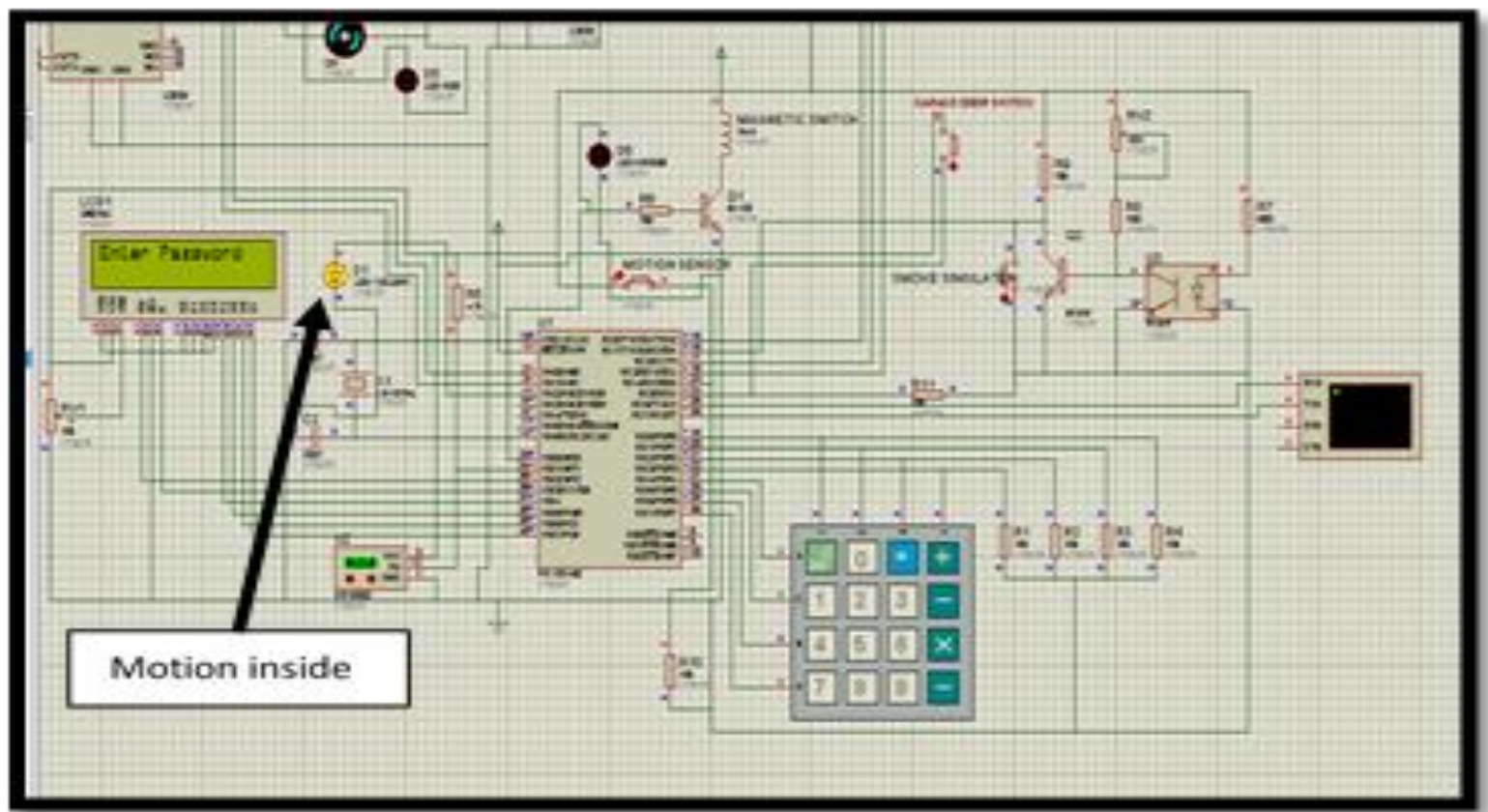

Fig-8: Detecting Motion inside home. 


\subsection{Smoke Detection}

In case, there is a smoke in home smoke sensor detects the smoke then sends a signal to microcontroller to turn the extractor on, to take out the smoke from home, as shown in figure 9 .

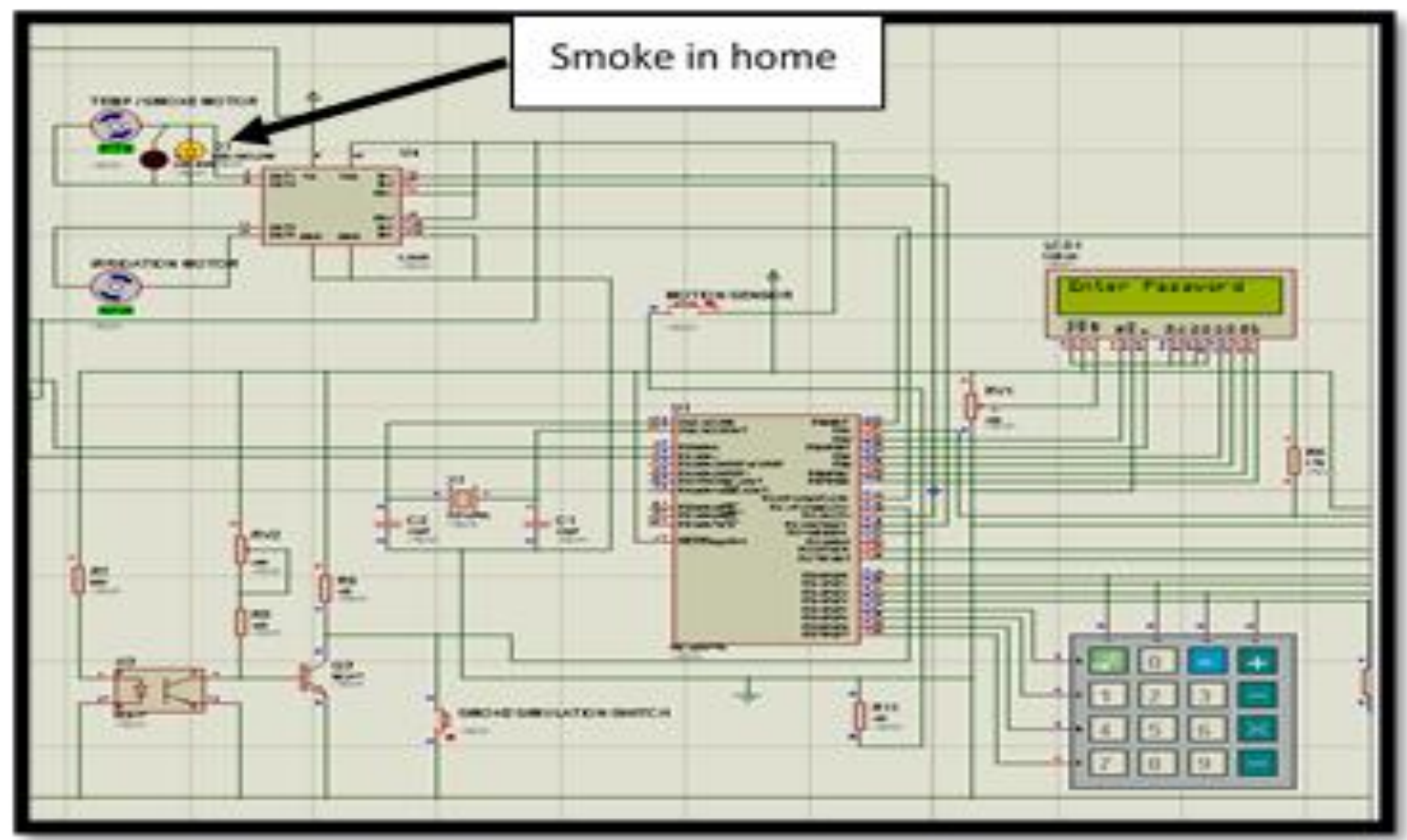

Fig -9: Smoke sensor ON

\subsection{Temperature Sensor}

If the thermometer detects an increase in room temperature, it sends control signal to the microcontroller interfaced to it, hence the microcontroller take necessary action like turn the fan on which is work as an air-conditioning to maintain the room temperature at the desired value, as shown in figure 10 .

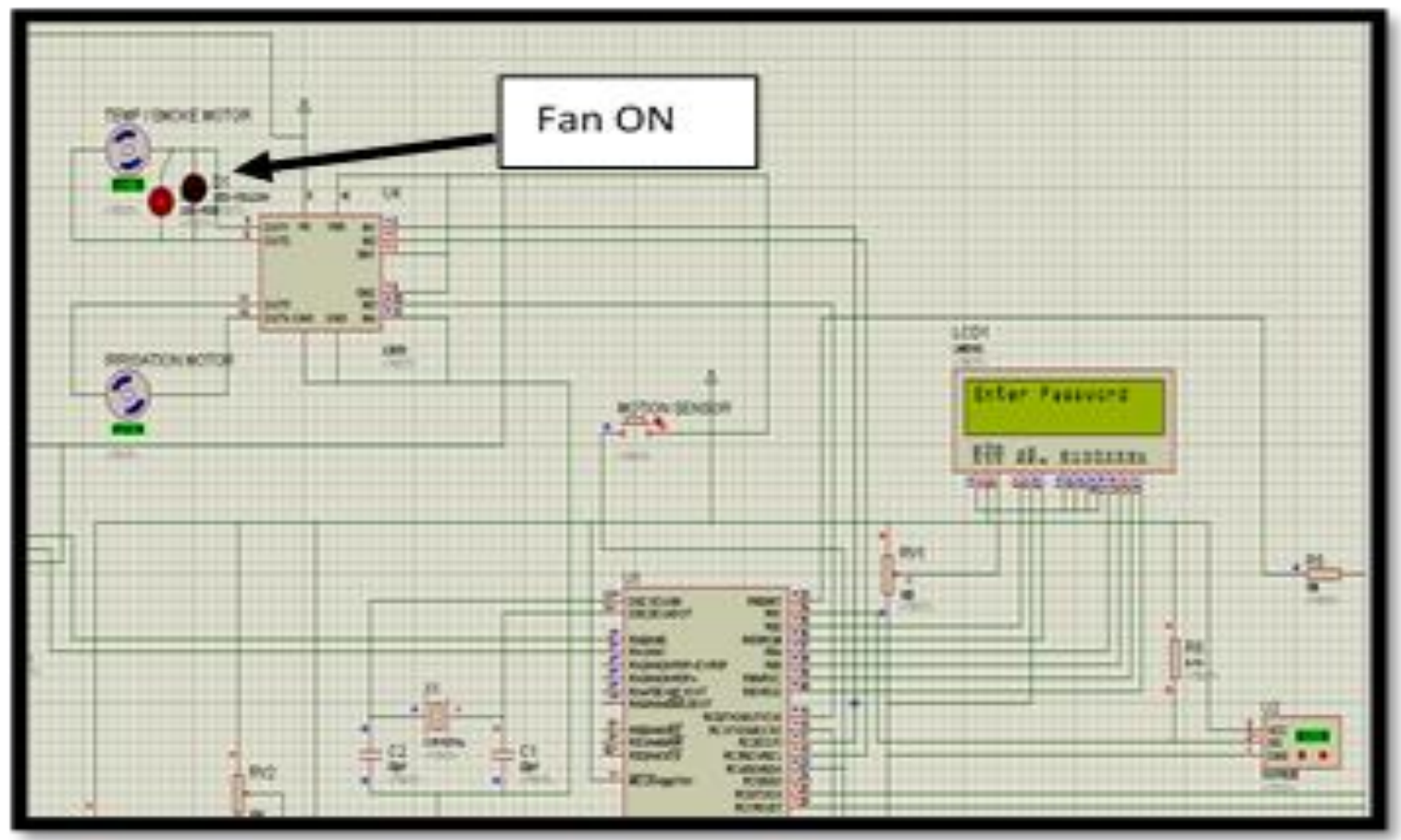

Fig-10: Simulation of air-condition on for cooling 


\subsection{Garage Door}

In this project we control garage door by two ways; wireless and manually. Wireless control is done by using GSM module technology that allow the owner to send a
SMS message to GSM module then GSM module send a signal to microcontroller to open the garage door . while in manual control which means there is a switch near garage door to open and close the door, as shown in figure 11.

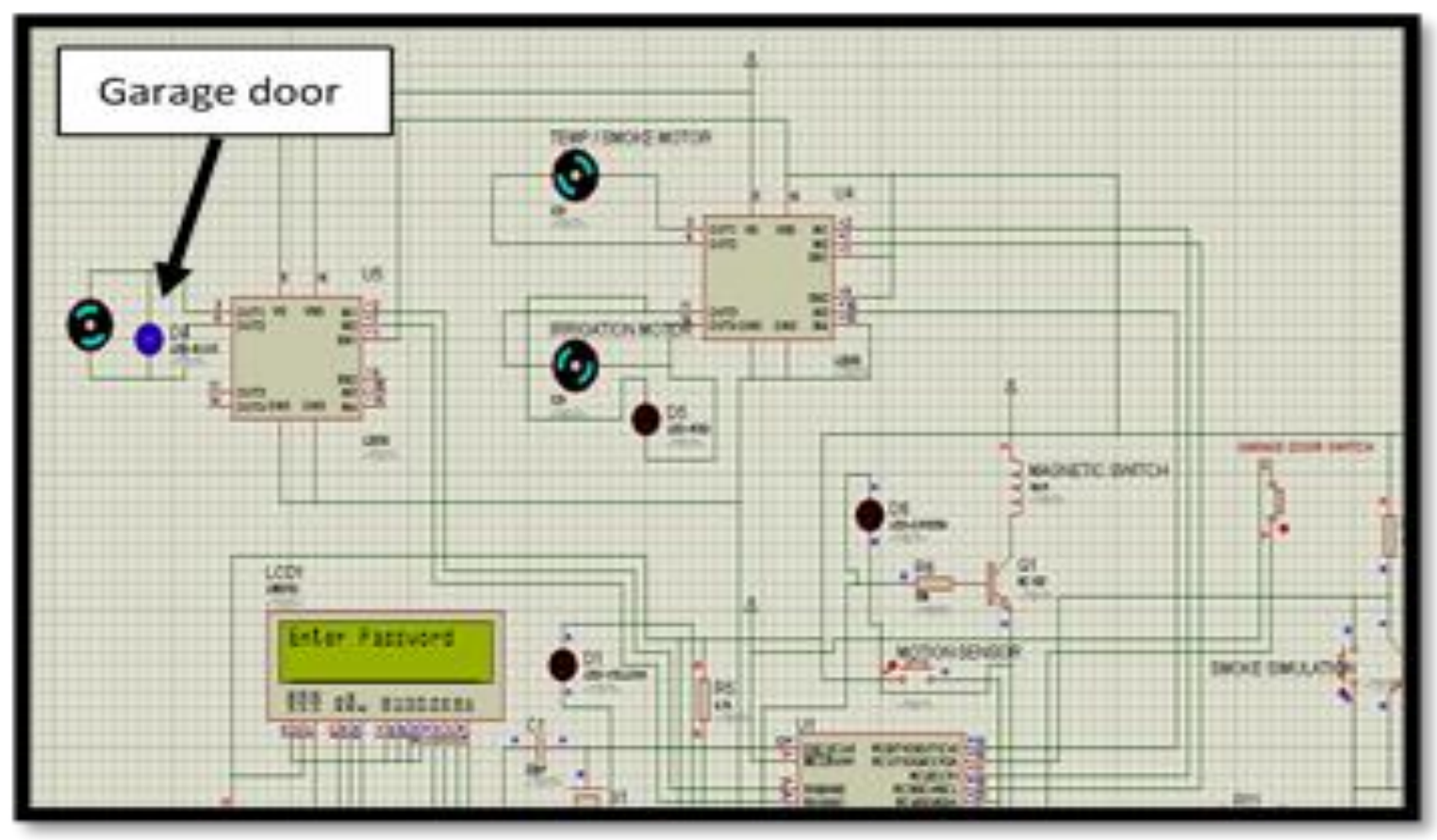

Fig-11: Garage door open

\subsection{Irrigation System}

The irrigation control system is done by using pump which operates on timer as shown in figure 12.

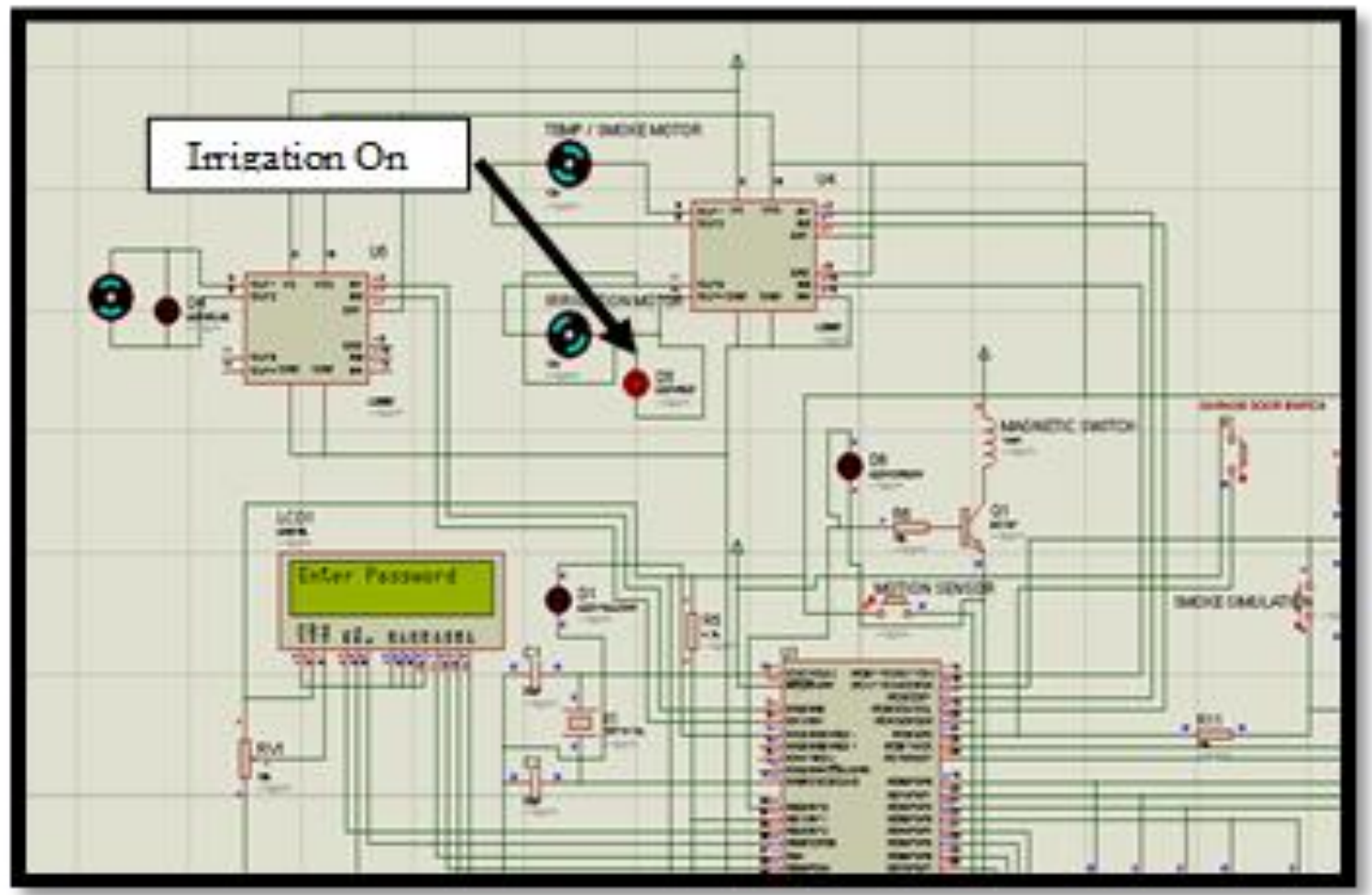

Fig-12: Irrigation system 
Our proposed prototype for smart home is implemented and is illustrated in figure $13 \& 14$

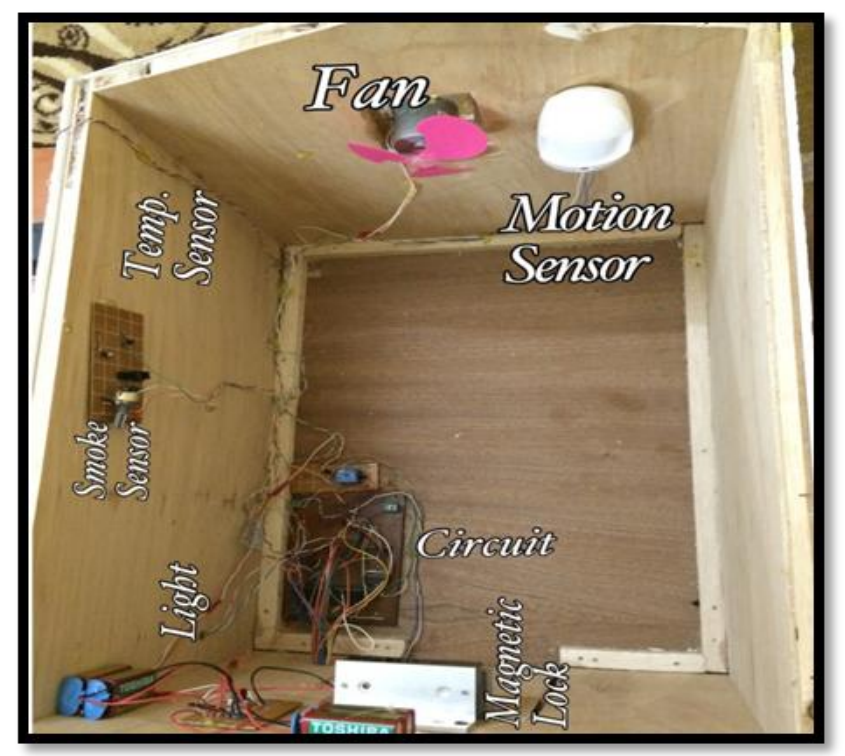

Fig-13: Plan 3d view of smart home prototype

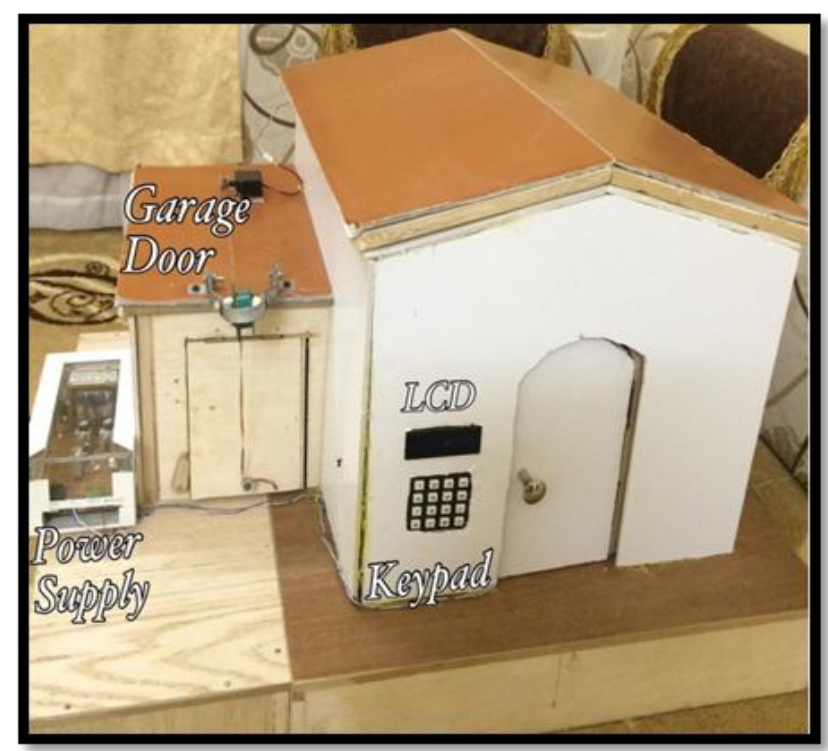

Fig-14: Front 3d view of smart home prototype

\section{CONCLUSION}

Our project goal was to implement a smart home system by controlling the electronic devices at home remotely with a mobile phone and to receive alerts on intrusion and movement around restricted places. The goal was achieved successfully. The devices were controlled by sending instructions as an SMS and the alerts were received as an SMS as well. A passive infrared sensor were used as detectors to detect the intrusion and movement around the restricted premises respectively. A temperature sensor was used as a heat detector and a led light was used to show the demonstration of an electronic device management. SIM900 GSM module was interfaced withPIC18F452 microcontroller properly. The SIM900 GSM module was used for communication between the microcontroller unit and the mobile station. The mobile phone did not need to have any special application or hardware to be used as a mobile station. Any mobile phone supporting the SMS could be used as a mobile station. The developed GSM based security system gives good response to the sensor and sends SMS when it detects the fire or temperature is increased above desired level. As well, it can send a message to the user for action when the owner is out of station and the home is locked which helps us to keep more secure of our home. Moreover, owner can control loads (on/off) automatically by mobile using GSM technology from anywhere. Flexibility with the technical customization and economy are the main advantages of the design . This project will have a large effect to the living standard of human being. In the system, a lot of other features can be added to the user's requirement depending upon the situation.

\section{REFERENCES}

[1]. E Wong "A Phone-Based Remote Controller for Home and Office Automation", IEEE Trans Consumer Electron, vol.40, No. 1, pp. 28- 33, 1995.

[2]. J. Burroughs, "X-10 home automation using the PIC16F877A,” Lamp, vol. 10, article 10, 2010.

[3]. A. Z. Alkar, and U. Buhur, "An Internet Based Wireless Home Automation System for Multifunctional Devices,"IEEE Transactions on Consumer Electronics, vol. 51, no.4, pp. 1169-1174, 2005.

[4]. Piyare, R., Tazil M., "Bluetooth based Home AutomationSystem using Cell Phone", IEEE $15^{\text {th }}$ International Symposium on Consumer Electronics, pp. 192-195, 2011.

[5]. Jayashri Bangali and Arvind Shaligram" Design and Implementation of Security Systems for Smart Home based on GSM technology", International Journal of Smart Home Vol.7, No.6 (2013), pp.201-208.

[6]. Yuksekkaya, B., Kayalar, A.A., Tosun, M.B., Ozcan, M.K., Alkar, A.Z., "A GSM, Internet and Speech Controlled Wireless Interactive Home Automation System", IEEE Transactions Consumer Electronics, vol. 52, no. 3, pp. 837-843, 2006.

[7]. Y. Zhao and Z. Ye, "A Low Cost GSM/GPRS Based Wireless Home Security System", IEEE Transactions on Consumer Electronics, vol. 54, no. 2, pp. 567-572, 2008.

[8]. GSM Based Home Automation with Security (Using Microcontroller) Dr. Shaik Meeravali 1, P. Sai Prasad 2 International Journal of Engineering Research \&Technology (IJERT) Vol. 2 Issue 9, September 2013ISSN: 2278-0181.

[9]. http://www.microchip.com/wwwproducts/Device s.aspx?product=PIC18F452

[10]. http://www.rhydolabz.com/documents/gps_gsm/si 900_rs232_gsm_modem_opn.pdf 